\title{
Improvement of the Movement Speed of Tying Fishing Line Automatically
}

\author{
Kaito Uemura ${ }^{\text {a }}$, Takumi Sasaki ${ }^{a}$, Yuhki Kitazono ${ }^{\mathrm{a}, *}$ \\ ${ }^{a}$ National Institute of Technology, Kitakyushu College,5-20-1 Shii, Kokuraminami-ku, Kitakyushu-city, Fukuoka \\ 802-0985, Japan \\ *Corresponding Author: kitazono@kct.ac.jp
}

\begin{abstract}
The current fishing population is getting small. As one of the causes, it is conceivable that young people in their $20 \mathrm{~s}$ and 30 s are getting away from fishing due to overuse smartphones. Therefore, We thought that the population of fishing may increase by being able to do fishing more easily, this system was developed and focused on the action of tying fishing lines which are indispensable for fishing. This system requires only one hand, and it is easy for not only handicapped people but also fashionable people to tye fishing line. This system is also for cold weather countermeasures. This system will increase the fishing population in $\operatorname{Japan}^{(\mathbf{1})}$.

We aim for getting rid of the boredom of waiting by impr oving this system, and improving movement speed, and eve $\mathrm{n}$ anyone being able to enjoy fishing casually.
\end{abstract}

Keywords: fishing, line, fishing hook, automatically.

\section{Introduction}

The current fishing population is getting small. According to Leisure White paper $2018^{(2)}$, as shown in Fig.1, it is estimated that the fishing population in 2017 is about 6.4 million people and the lowest in 13 years from 2005 to 2017. Also, compared with 2006, which was the highest in 13 years from 2005 to 2017 , it is estimated that the fishing population in 2006 is about 12.9 million people, it has decreased by half in $2017^{(3)}$. There are some causes. One of the causes is shown that the law on the prevention of damage on ecosystems because of specified alien species which came into force in 2005. The black bass which is popular in fishing game was identified. The second cause is that the many port facilities prohibited to enter the restricted area is expanding for counterterrorism. The third cause is rising price of fishing boats. It is mainly due to the high oil price. The most influential cause is that it is conceivable that young generations in their 20 s and 30 s are getting away from fishing due to overuse smartphones. In addition, fishing is ranked tenth in sports-related events by whole gender and age group participation rate, males only is ranked seventh, young males and all ages females is out of rank, it is understood that it is unpopular with women and young people $^{(1)}$.

Additionally, the domestic market of fishing supplies according to Leisure White paper $2018^{(2)}$ is slightly rising in recent years, as shown in Fig.2, but in the whole 13 years from 2005 to 2017, It is understood that it is decreasing ${ }^{(3)}$. However, comparing the decrease in the fishing population and the trend in the fishing tackle market, the decrease in the fishing gear market is moderate, and it indicates that the demand for fishing tackle is still high.

Furthermore, in 2017, a questionnaire was conducted to 210 students of National Institute of Technology, Kitakyushu College. As a result, $64 \%$ of the people answered that they did not go fishing in response to the question, "Did you go fishing in the last 2 or 3 years?" The results are shown in Fig.3. In addition, 46 out of 76 women out of 210 respondents answered that they did not go fishing ${ }^{(1)}$.

So last time, we proposed the "Fishing Support System: Hereinafter referred to as FSS) " as a method of supporting fishing so that the fishing population will increase in the future by using this system in Kitazono laboratory. This system can help replace bait into a fishing hook automatically $^{(1)}$.

Furthermore, the action of tying a fishing line is necessary for almost all fishing. A graph summarizing the Domestic shipment scale of fishing tackle in 2018 of the 22nd 
"Domestic Demand Trends Research Report on Fishing Tackle" published to JAPAN FISHING TACKLE MANUFACTURERS ASSOCIATION is shown in Fig.4 ${ }^{(4)}$. Looking at Fig. 4, except for high-class items such as fishing rods and fishing reels, domestic shipments of fishing hooks, fishing lines and lures are as it can be seen that it is large. Since these are relatively inexpensive consumables, it can be inferred that the large domestic shipment scale is consumed by that much. Consuming these means that the rocks and seaweed on the seabed are hooked fishing hook and the line are broken, so accordingly it is thought that the chances of connecting the fishing line to the hook and the lure will necessarily increase.

Also, the number of people going fishing is changed depending on the season. Fig.5 shows the percentage of the month with many times to go fishing in angler trend surveys ${ }^{(5)}$. According to this, it can be understood that the number of visiting fishing spot decreases in December, January, February and so on. One of the causes is that although the hand can be numb in the cold season and the line cannot be tied well and the line cannot be tied well even with gloves

From such a background, we felt that we need an apparatus for automatically tying a fishing line without using hands many times, and examined how to develop it. As a previous study, a device has been developed that supports tying a fishing hook at "uchikakemusubi" (6). Hooks often used in bait fishing have not holes that ties the fishing line, and are in the form of protrusions. On the other hand, lure, and hooks for soft lure, and fly have holes in the part tying fishing line, and to thread there and tying, the way of tying is different from that hooks for bait fishing. In this system, we think that a system capable of doing so would be necessary because it is difficult to tie the fishing line to a hook of the type that ties the fishing line to the hole. First of all, if we developed an apparatus for automatically tying fishing line, we thought that it would be easy to apply to the development of equipment that supports tying fishing line manually. Therefore, following the above FSS concept. we developed new automatic system for tying fishing line to fishing hook or lure. In this system, people with disabilities are also targeted, so even people without one arm can be attached, and it is possible to participate in fishing easily while wearing gloves or wearing fashion such as nails, and finish developed a system that makes you want to go fishing.

We confirmed that operation. As a result, I found three problems.

First, the operation of the machine is slow

Second,A thread loosens in the middle of movement

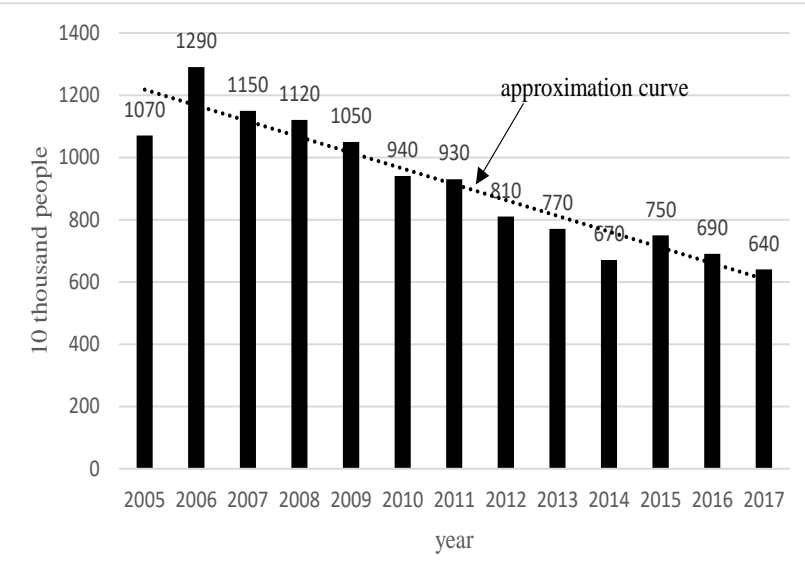

Fig. 1. Changes in the fishing population.

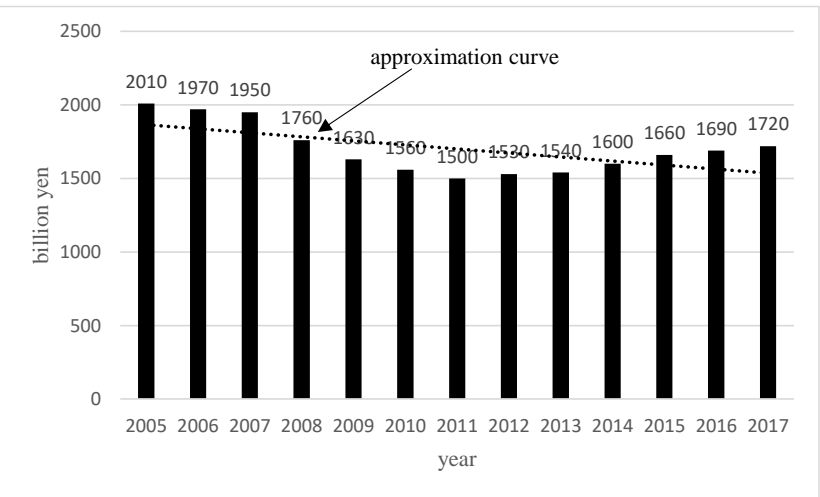

Fig. 2. Changes in the fishing market.

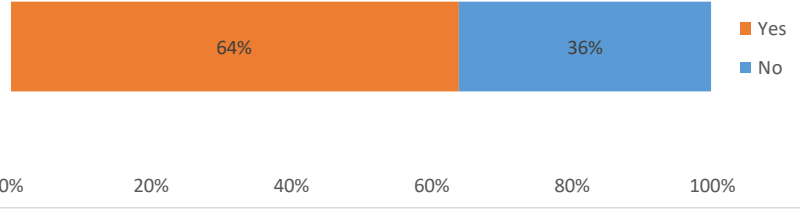

Fig. 3. Survey results.

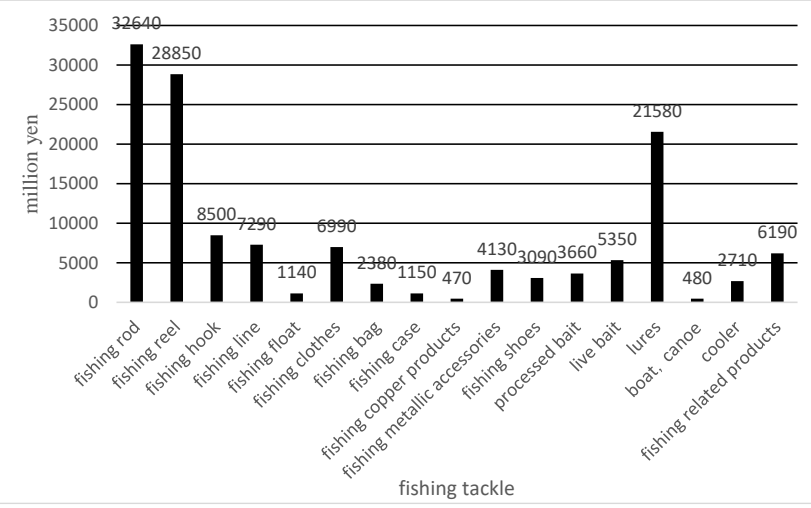

Fig. 4. Domestic shipment scale of the fishing tackle. 


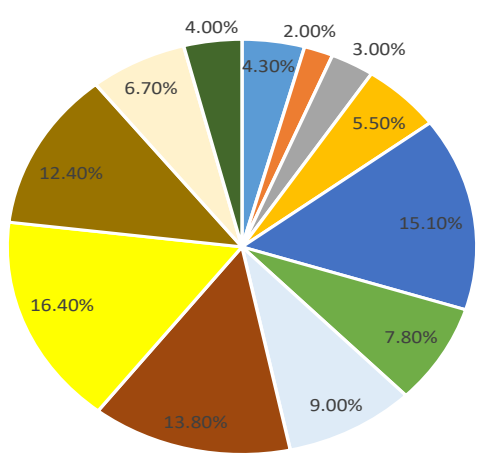

- January

- February

- March

- April

- May

- June

- July

- August

- September

- October

November

- December

Fig. 5. Percentage of the month with many times to go fishing.

Third, find the needle hole and position

adjustment automatic.

Two of the reasons can be settled by making movement speed early

Based on the above, we make various improvement on a machine. We focused on a point called the speedup of the movement and improved the device.

\section{Structure}

An overview of the created system is shown in Fig.6. This system operates in the following steps (1) to (13). The total size is $300 \mathrm{~mm}$ length, $400 \mathrm{~mm}$ wide, and $300 \mathrm{~mm}$ high.

(1)Place the line on a specified pedestal, passing through the center of the wrap line system from slit.

(2) Press the start button.

(3) Move the servomotor(1) and hold the line.

(4) Close the chuck and grab the line. At the same time, start-up the Needle threader system, and thread Needle threader to fishing hook hole.

(5) Rotate the belt to the back and thread the fishing line to Needle threader.

(6) Start-up the Needle threader system, and unplug Needle threader from fishing hook hole.

(7)Hold the line passing passed the hook hole with an arm system.

(8) Start-up Keep the Line ring system(1).

(9)Move the arm so that the line passes under the Keep the Line ring system (1). Then hook the line on the hook part of the Wrap line system and release the line.

(10)Start-up Wrap line system.

(11) Grab a line on the hook part of the Wrap line system with an arm and remove it.

(12) Start-up Keep the Line ring system(2).
(13) Move the arm so that the line passes under the Keep the Line ring system (2). Then hook the line on the hook part of the Keep the Line ring system(1).

(14) Take down a Keep the Line ring system(1).

(15) Grab a line on the hook part of the Keep the Line ring system(1) with an Chuck system and remove it. Then hook the line on the hook part of the Keep the Line ring $\operatorname{system}(2)$.

(16) Take down Keep the Line ring system(2), and open a chuck. After that, the user removes a line from hook part of Keep the Line ring system(2).

These operations are controlled by Arduino using eight servomotors, three DC motors and one solenoid coil. In addition, it is procedure (1)(2)(16) to use a hand with this system, and all can be done with one hand.

Based on the above, we make various improvement on a machine. We focused on a point called the speedup of the movement and improved the device.

Taking the above-mentioned point into consideration, we performed the following improvement in an operating ti me aspect.

First, shorten the wait time for each device and perform parallel computation of the movement Shortening of some movement went, too

The following time was shortened about each movement by regulating wait time I show the result of the experiment in the Table1 to Table3.

Second, changed a motor and the hand for movementrelated improvement. Fig5 is the picture of hands before and after improvement. It is thought that speed becomes fast by

Table 1. Shortened time.

\begin{tabular}{|l|l|l|l|l|l|l|}
\hline $\begin{array}{l}\text { Number } \\
\text { of the } \\
\text { movement }\end{array}$ & 1 & 2 & 3 & 4 & 5 & 6 \\
\hline $\begin{array}{l}\text { Shortened } \\
\text { time[ms] }\end{array}$ & 0 & 0 & 350 & 1400 & 700 & 1400 \\
\hline $\begin{array}{l}\text { Number } \\
\text { of the } \\
\text { movement }\end{array}$ & 7 & 8 & 9 & 10 & 11 & 12 \\
\hline $\begin{array}{l}\text { Shortened } \\
\text { time[ms] }\end{array}$ & 700 & 700 & 350 & 700 & 350 & 350 \\
\hline $\begin{array}{l}\text { Number } \\
\text { of the } \\
\text { movement }\end{array}$ & 13 & 14 & 15 & 16 & & \\
\hline $\begin{array}{l}\text { Shortened } \\
\text { time[ms] }\end{array}$ & 700 & 350 & 700 & 700 & & \\
\hline
\end{tabular}




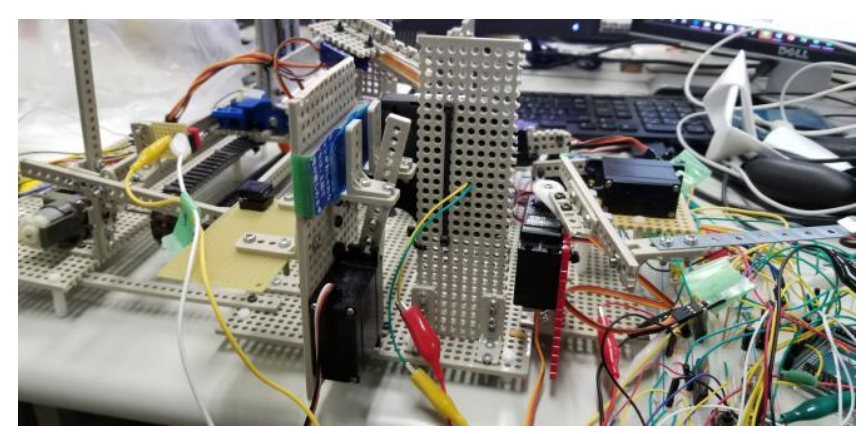

(a) Side view

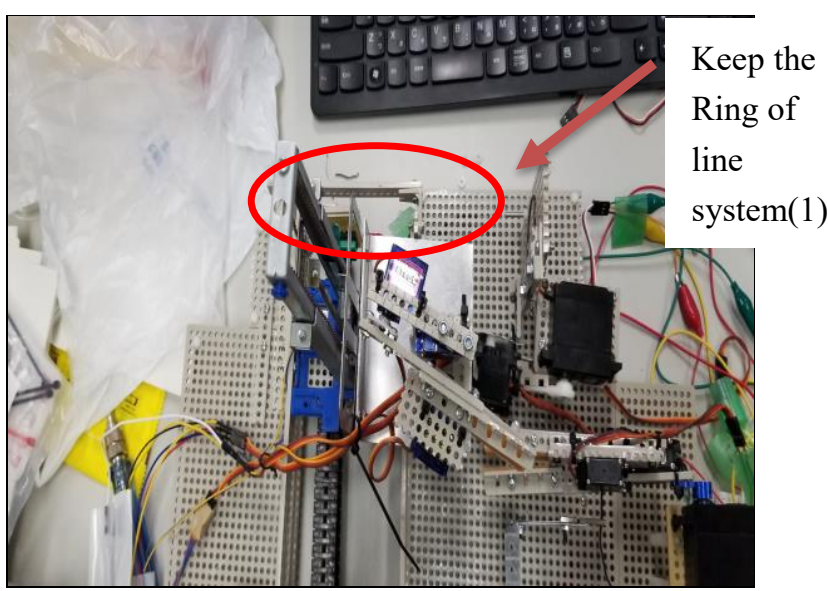

(b) top view1

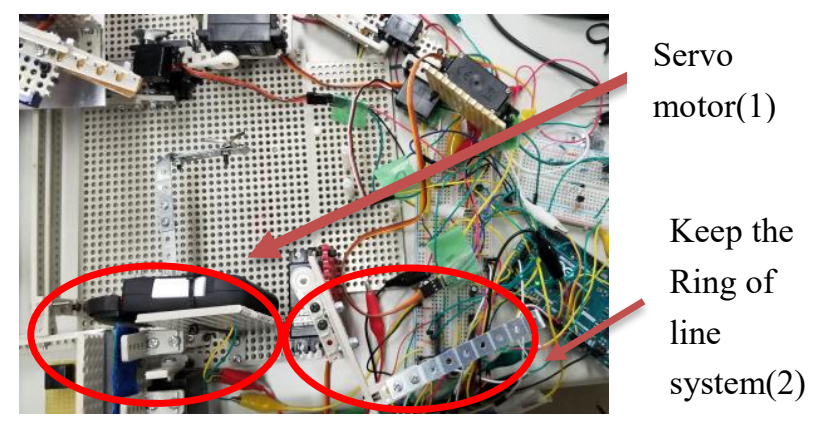

(c) top view2

Fig. 6. Overall system diagram.

giving the output. The output grows big by increasing the size of the motor one size. Distance to change decreases when I make a hand big.

\section{Experiment}

We carried out following experiments about the device which I improved this time.

- We measure operating times five times and make the mean.

- Compere it with data before the improvement

We show the result of the experiment in the Table 2.

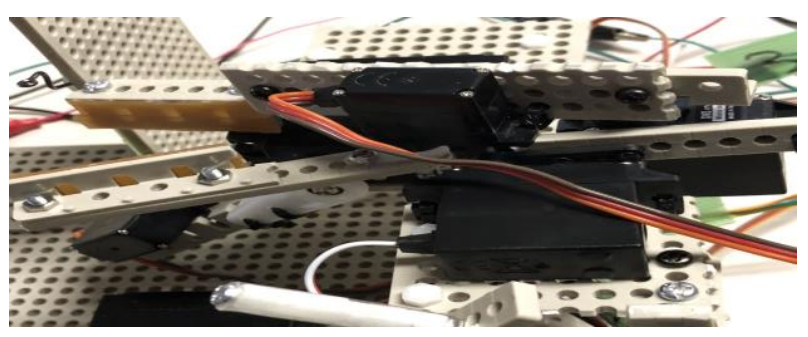

(a) Hand before improvement ${ }^{(8)}$

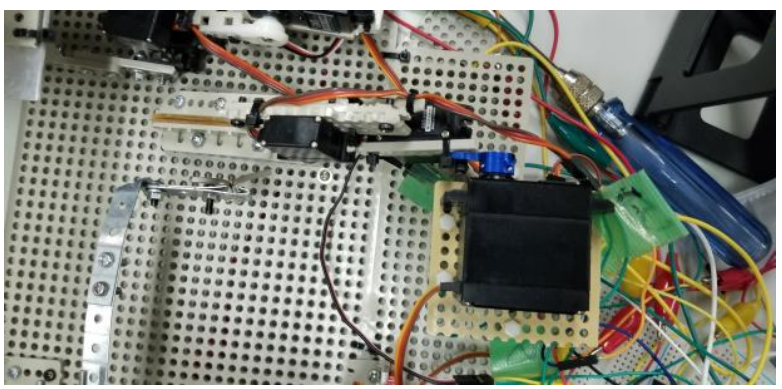

(b) Hand after improvement

Fig. 7. Hand.

Table 2. Operating speed.

\begin{tabular}{|c|c|c|c|c|c|c|}
\hline & 1 & 2 & 3 & 4 & 5 & average \\
\hline $\begin{array}{c}\text { After the } \\
\text { improvement[s] }\end{array}$ & 22 & 25 & 24 & 23 & 25 & 23.8 \\
\hline $\begin{array}{c}\text { Before the } \\
\text { improvement[s] }\end{array}$ & 34 & 40 & 43 & 37 & 39 & 38.6 \\
\hline
\end{tabular}

\section{Conclusions}

From Table 1 the machine had been able to shorten the mean of the movement speed $38.4 \%$. We were able to meet the specifications that We assumed about the movement speed than the above. We cannot yet improve the movement success rate. We want to raise success probability in future while maintaining movement speed. It also detects the hole of the needle and wants to allow a position to automatically make it adjustment.

\section{References}

(1) Shun Oyabu and Yuhki Kitazono, Fishing Support System -Replacing the bait into a fishing hook automatically-, The Japanese Journal of the Institute of Industrial Applications Engineers, Vol.6, No.1, 59-67 
(2) Japan Productivity Center, Leisure White paper 2018, Productivity publication, 2018.

(3) tektosense, Fishing population Trends in the fishing market

https://www.tektosense.co.jp/index.php/archives/4509

(4) JAPAN FISHING TACKLE MANUFACTURERS ASSOCIATION, Transition of the Domestic shipment scale of fishing tackle (2016-2019 prediction, 17 product categories), http://www.jaftma.or.jp/standard/pdf/20190201_22kjdc $\underline{\text { h.pdf }}$

(5) ishizueshin, Latest edition Fishing angler trend survey questionnaire (1)- Aggregate progress, http://www.tsuri123.com/enq/enq.cgi?id=Shin\&mode= $\underline{\text { result }}$

(6) GLOBERIDE, Inc. DAIWA, Fast attack hook tying device,

http://www.daiwa.com/jp/fishing/item/terminal_tackle/ others_te/harimusubiki/index.html

(7) GLOBERIDE, Inc. DAIWA, clinch knot,

(8) http://daiwa.globeride.jp/column/line/contents/01/index $\underline{. h t m l}$

(9) Takumi Sasaki and Seiichi Serikawa and Yuhki Kitazono Fishing Support System Tying Fishing Line Automatically 